\title{
Öğretmen Adaylarının Matematik Öğretimine Yönelik Eğitsel Dijital Oyun Tasarımlarının ve Tasarım Sürecine ilişkin Görüşlerinin İncelenmesi
}

\author{
Hatice Yıldız Durak $^{* 1}$ ve Fatma Gizem Karaoğlan Yılmaz ${ }^{2}$
}

Öz

\author{
Anahtar Sözcükler \\ Öğretmen adayları \\ Matematik eğitimi \\ Eğitsel dijital oyun \\ tasarımı \\ Makale Hakkında \\ Gönderim Tarihi \\ 29 Haziran 2018 \\ Kabul Tarihi \\ 29 Temmuz 2019 \\ Makale Türii \\ Araştırma Makalesi
}

DOI: 10.12984/egeefd.439146

\section{An Investigation of Prospective Teachers' Educational Digital Game Designs for Mathematics Teaching and Their Opinions on the Design Process}

\section{Abstract}

The aim of this study is to examine the pre-service teachers' views on the design process in designing an educational digital game for mathematics teaching. The case study method was used for the research design. In addition to the qualitative data, the digital games prepared by the participants were analyzed by the researchers. The participants were 30 pre-service teachers studying in the third year of Department of Mathematics Education at a public university. In this study, semi-structured interview form was used and student projects were examined. Participants were involved in designing an educational digital game aimed at teaching 14 weeks of Mathematics. The results of the study indicated that the process of designing educational digital games, according to the pre-service teachers' views, mostly allowed them to develop problem solving skills in the academic field, promoted creativity, and developed competencies to use technology in mathematics. In the context of technology competence, pre-service teachers showed the most improvement in gaining competence in technology use.
Keywords

Teacher candidates Mathematics education Educational digital game design

Article Info

Received June 29, 2018 Accepted

July 29, 2019

Article Type

Research Paper

Atıf: Yıldız Durak, H. ve Karaoğlan Yılmaz, F. G. (2019). Öğretmen adaylarının matematik öğretimine yönelik eğitsel dijital oyun tasarımlarının ve tasarım sürecine ilişkin görüşlerinin incelenmesi. Ege Eğitim Dergisi, 20(1), 262-278. doi: 10.12984/egeefd.439146

\footnotetext{
Sorumlu Yazar/Corresponding Author

1 (D) Bartın Üniversitesi, Fen Fakültesi, Bilgisayar Teknolojisi ve Bilişim Sistemleri Bölümü, Türkiye, hatyil05@gmail.com

2 (D) Bartın Üniversitesi, Fen Fakültesi, Bilgisayar Teknolojisi ve Bilişim Sistemleri Bölümü, Türkiye, gkaraoglanyilmaz@ gmail.com
} 


\section{Extended Abstract}

\section{Introduction}

The use of games in education has been rapidly developing in line with the advancement of technology. Educational games are expected to be integrated into the learning process with a steady increase in the intensity of using information technology for the education of K-12 students. The literature review showed that the use of educational games makes a positive contribution to the learning process. Educational games increase the interest and attendance of students in comparison to traditional classroom practices; make lessons entertaining, improve academic performance, and contribute to the development of students' motivations. Educational games increase the skills of critical thinking, creative thinking, decision making, and evaluation with game-based learning scenarios. Educational games also support social and technical skills of students. Critical thinking and problemsolving are considered to be the most important learning skills of the $21^{\text {st }}$ century and these skills can be enhanced with educational games.

There are various obstacles in terms of the integration of educational games into education. First of all, teachers have technological and pedagogical deficiencies. Teachers have an important role in integrating educational games into education. Although the majority of teachers have positive thoughts on using educational games in learning environments, very few of them use these games in educational settings. The main obstacle that teachers confront in terms of educational games is the lack of skills in designing and using educational games. Teachers also have this common belief that they need to put a great effort to learn about using educational games and about their design, in addition to the heavy workload they already have. At this point, it can be argued that the teachers face technical difficulties in using educational games. On the other hand, some teachers are not aware of the potential of the pedagogical opportunities and the content presented by educational games. Therefore, they think that it is not necessary to integrate educational games into education and training.

Due to these reasons, teachers should be able to acquire technical skills related to educational games and be aware of the potential contributions of the educational games. The present study aimed to provide experience for pre-service teachers on the use of educational games. In this study, pre-service teachers were tried to gain experience about educational games. Pre-service teachers were chosen to be included in the study as they will become teachers of the future.

\section{Method}

The aim of this study is to investigate prospective teachers' educational digital game designs and their views on the design process for mathematics teaching. In this study, case study of qualitative research method was used to determine the opinions of pre-service teachers on the design of educational digital games.

The present research study was conducted with $3^{\text {rd }}$ year pre-service teachers of the Department of Mathematics Education, who attended the elective course titled Educational Computer Games Design. Participants of the study consisted of 30 university students studying at a state university in Turkey in the fall semester of the 20172018 academic year. The age of the university students ranged between 20 to 24 years old. Of the participants, 13 were male, and 17 were female. Semi-structured interview form was used to collect data. Student projects were also examined.

\section{Findings}

The research study investigated the factors that pre-service teachers considered in terms of the process of designing educational digital games for teaching mathematics. In the scope of the study, the use of color, background, character selection, instruction, level of knowledge, and branch structure were examined. The findings revealed that the majority of games prepared by pre-service teachers do not include adaptation, time limitation and directives for use, according to the preliminary knowledge levels. Pre-service teachers reported that they have educational awareness yet they cannot realize their designs due to technical shortcomings and time constraints.

According to research findings, pre-service teachers made the most academic progress in the process of designing educational digital games. The process of designing educational digital games have improved their ability to use mathematical technology, and accordingly enhanced their problem-solving skills, creativity, and academic ability. According to the interview results, pre-service teachers stated that they were provided a suitable environment for improving their problem-solving abilities. In the context of technology proficiency, the findings demonstrated that pre-service teachers made the most progress in acquiring technology competence. In 
terms of the field knowledge, game designed activities seem to contribute to the process of teaching mathematics.

\section{Discussion and Conclusion}

The present study revealed that the provision of the aforementioned elective course in primary school mathematics teaching can be effective in terms of realization of game design and game designed activities.

Depending on the majors of the pre-service teachers, future studies conducted on digital games may address the issues of game design and the design of the game concerning differentiation. According to Becker (2007), preservice teachers need guidance on when, how, and which games will serve their educational purposes in particular. From this point of view, it may be suggested that the pre-service teachers' education should include more courses about designing educational games. In addition, Bourgonjon et al. (2013) suggest that pre-service teachers should be informed of the practices related to educational games before experiencing game design.

It is seen that the most challenging situation in the process of designing digital games is the design of game scenarios. It is thought that, as a new method, teacher candidates have problems in teaching mathematics with games and therefore it is difficult to present content with a game and make it a scenario. According to Werbach and Hunter (2012), game scenarios and gamification activities should focus on intrinsic motivation rather than exogenous motivation to contribute to learning performance. For this reason, scenarios supporting autonomy, competence and sense of commitment should be developed in game design processes. Another reason why teacher trainees have difficulty in determining game scenarios may be due to the effort to ensure that the scenarios of educational digital games increase the motivation.

Data were obtained according to the participants' own statements. The participants of this study have taken computer use courses in previous periods and have realized digital story design in many courses. This may have an impact on the process and results of the study. On the other hand, the fact that this course is applied in elementary school mathematics education and was an elective may have an impact on the results of the study in the realization of game design activities. In future studies, prospective teachers may study whether there is a difference in their views on digital games, game designs and their opinions about the design of games depending on their majors. Experimental studies can be conducted to evaluate the effectiveness of educational digital games designed in future studies. The effects on the students using educational digital games designed in this way can also be evaluated. In addition, eye movement tracking technology can be used to examine the design features of the designed games. The generalizability of this study conducted with mathematics teacher candidates can be repeated with the prospective teachers studying in the other departments. 


\section{Giriş}

Eğitimde oyun kullanımına yönelik uygulamalar, teknolojideki gelişmeler doğrultusunda hızlı bir şekilde gelişmektedir (Sardone ve Devlin-Scherer, 2010). K 12 düzeyindeki öğrencilerin bilişim teknolojilerini kullanım yoğunluğunun sürekli artması (Durak ve Seferoğlu, 2018) ile, eğitsel oyunların öğrenme süreciyle bütünleştirilmesini kolaylaştıracaktır (Furio, Gonzalez-Gancedo, Juan, Seguí ve Rando, 2013).

Alanyazın incelendiğinde, eğitimde oyunların kullanımının eğitime olumlu yönde katkıları olduğu görülmüştür. Eğitimde kullanılan eğitsel oyunlar, geleneksel sınıf uygulamalarına göre öğrencilerin ilgi ve derse katılımlarını arttırmakta (Rosas ve diğ., 2003); dersi eğlenceli hale getirmekte (Berns, Gonzalez-Pardo ve Camacho, 2013; Rosas ve diğ., 2003), akademik performansı arttırmakta (Dede, Ketelhut ve Nelson, 2004; Gros, 2007) ve öğrencilerin güdülenmelerinin olumlu yönde gelişmesine (González-González ve Blanco-Izquierdo, 2012) katkıda bulunmaktadır. Eğitsel oyunlar oyuna dayalı öğrenme senaryoları ile eleştirel düşünme, yaratıcı düşünme, karar verme ve değerlendirme becerilerini artırmaktadır (Karadağ, 2015). Ayrıca eğitici oyunlar öğrencilerin sosyal ve teknik becerilerini desteklemektedir (Berns ve diğ., 2013; González-González ve BlancoIzquierdo, 2012). Eleştirel düşünme ve problem çözme, 21. yüzyıl öğrenme becerilerinin en önemlisi olarak kabul edilmektedir ve eğitsel oyunlar ile bu becerilerin geliştirilebileceği düşünülmektedir (Day, Arthur ve Gettman, 2001; DeLisi ve Wolford, 2002; Gee, 2007).

Eğitsel oyunların, genellikle öğrencilerin olumsuz tutuma sahip oldukları matematik eğitimine de önemli katkıları olduğu görülmektedir. Foster, Katz-Buonincontro ve Shah'a (2011) göre eğitsel oyunlar matematik eğitiminde öğrencilerin derse katılımlarının arttırmanın ve etkin öğrenmeyi sağlamanın en iyi yoludur. Matematik eğitiminde eğitsel oyun kullanımı öğrenmeye yönelik güdülenmelerini arttırmakta, matematik konularıyla ilgili soyut konulara dair somut deneyimler yaşatmaktadır (Stupiansky, Stupiansky ve Nicholas, 1999). Buradan hareketle matematik eğitiminde oyun kullanımının daha etkili bir matematik öğretimi sağlayacă̆ı söylenebilir.

Eğitsel oyunların eğitimle bütünleştirilmesinde bazı engeller vardır (Güleroğlu, 2015). Bu engellerin başında öğretmenlerin teknolojik ve pedagojik yetersizlikleri gelmektedir (Sancar- Tokmak, 2014). Çünkü eğitsel oyunların eğitimle bütünleştirilmesinde öğretmenlerin önemli rolü vardır. Noraddin ve Kian’a (2015) göre öğretmenlerin çoğunluğu eğitsel oyunları öğrenme ortamlarında kullanma konusunda olumlu düşüncelere sahip olsalar da, çok azı bu oyunları eğitim ortamlarında kullanır. Razak, Connolly ve Hainey’e (2011) göre öğretmenlerin eğitsel oyunlar konusundaki olumlu düşüncelerini uygulamaya dökme noktasında engel oluşturan durum eğitsel oyun tasarlama ve kullanma konusundaki becerilerden yoksun olmalarıdır. Nitekim alanyazında öğretmenlerinin teknolojiyi eğitimle bütünleştirme deneyimleri üzerinde teknik becerilerinin önemli etkisi olduğu vurgulanmıştır (Durak ve Seferoğlu, 2017; Sarıtepeci, Durak ve Seferoğlu, 2016; Yıldız, Sarıtepeci ve Seferoğlu, 2013). Ayrıca öğretmenler, eğitsel oyunların tasarımı ve kullanımını öğrenmek ve kullanmak için çok fazla çaba gerektirdiğini ve zaten sahip oldukları ağır iş yüküyle bunun üstesinden gelemeyeceğini düşünmektedir (Kebritchi, 2010; Romero ve Barma, 2015). Bu noktada öğretmenlerin eğitsel oyunları kullanma konusunda teknik beceriler konusunda engellerle karşılaştığı söylenebilir. Öte yandan bazı öğretmenler eğitsel oyunlarının sunduğu içerik ve pedagojik firsatların potansiyelinin farkında değildir (Siko ve Barbour, 2012). Dolayısıyla da eğitsel oyunları tasarlama ve eğitimle bütünleştirilmesi için büyük çabalar göstermenin gerekli olmayacağını düşünmektedirler (Noraddin ve Kian, 2015).

Eğitsel dijital oyunlar, tüm eğitim kademelerinde, eğitim sürecinde öğrenci meşguliyetini arttırma, aktif katılımını sağlama (Kim, 2015) öğrenmeyi kolaylaştırma, güdülenmeyi, başarıyı arttırma ve derse karşı olumlu tutumlarının geliştirilmesi (Karataş, 2014) için önemli bir araçtır. Eğitim süreciyle eğitsel dijital oyunların bütünleştirilmesi için öğretmenlerin eğitsel dijital oyunlarla ilgili bilgi ve deneyim sahibi olmaları önemli görülmektedir. Somyürek’e (2014) göre Z kuşağında yer alan öğrencilerinin okuldan ve öğrenme öğretmen sürecinden beklentileri önceki kuşaklara göre giderek farklılaşmaktadır. $\mathrm{Bu}$ beklentileri karşılayabilme noktasında eğitsel dijital oyunların iyi bir çözüm olacağı düşünülmektedir. Bu nedenlerden dolayı öğretmenlerin eğitsel oyunlarla ilgili teknik becerileri kazanması sağlanmalı ve eğitsel oyunların eğitsel katkılarıyla ilgili potansiyelleri konusunda farkındalık yaratılmalıdır. Bu çalışmada eğitsel oyunlarla ilgili deneyim kazandırmak için öğretmen adaylarıyla çalışılmıştır. Öğretmen adaylarının seçilme nedeni, geleceğin öğretmenleri olacak olmalarıdır. Bu çalışmanın amacı, öğretmen adaylarının matematik öğretimine yönelik bir eğitsel dijital oyun tasarlama sürecine girdikten sonra sürece dair görüşlerini incelemektir. Bu amaç doğrultusunda aşağıdaki sorulara yanıt aranmıştır:

- Öğretmen adaylarının eğitsel dijital oyun tasarımları nasıldır?

- Oyun tasarlama etkinliklerinin mesleki gelişimlerine katkısı hakkındaki görüşleri nelerdir?

- Öğretmen adaylarının eğitsel dijital oyunlar hakkındaki deneyimlerinde zorlayıcı durumlar nelerdir? 
Yöntem

\section{Araştırmanın Deseni}

$\mathrm{Bu}$ çalışma, öğretmen adaylarının eğitsel dijital oyun tasarlama süreçlerine yönelik görüşlerini belirleyebilmek için bir olayı meydana getiren ayrıntıları tanımlamada ve görmede, olası açıklamaları geliştirmede ve değerlendirmede kullanılan durum çalışması (Gall, Borg ve Gall, 1996) ile yürütülmüştür. Durum çalışması desenlerinden ise bütüncül tek durum deseni tercih edilmiştir. Araştırmada seçilen durum Eğitsel Bilgisayar Oyunları Tasarımı dersini almakta olan Matematik Eğitimi Anabilim Dalı üçüncü sınıf öğrencileridir. Yin'e (2003) göre bu desen tek bir birim veya durumun ayrıntıları ile açıklığa kavuşturulmasında ve kendine özgü durumların araştırılmasında kullanılmaktadır.

\section{Çalıșma Grubu}

Araştırmanın katılımcılarını; 2017-2018 akademik yılı güz döneminde Türkiye'de bir devlet üniversitesinde öğrenim görmekte olan 30 üniversite öğrencisi oluşturmaktadır. Katılımcılar seçmeli Eğitsel Bilgisayar Oyunları Tasarımı dersini almakta olan Matematik Eğitimi Anabilim Dalı'nda üçüncü sınıfta okuyan öğretmen adaylarıdır. Öğretmen adaylarının yaşları 20 ile 24 arasında değişmektedir. Katılımcıların 13'ü erkek, 17'si kadındır. Çalışmanın amacı bağlamında, çalışma grubunun seçiminde amaçlı örnekleme seçim yöntemi örneklem biriminin belirlenmesinde kullanılmıştır. Amaçlı örnekleme araştırmanın amacına göre bilgi açısından zengin durumların seçilerek derinlemesine incelenmesine firsat sunan, amaçlanan özelliklere sahip bir veya daha fazla özel durumlarda kullanılan bir örnekleme yöntemidir (Büyüköztürk, Çakmak, Akgün, Karadeniz ve Demirel 2012). Amaçlı örnekleme, amaca uygun ve kolay erişilebilir örneklemin seçilmesini öneren bir yöntemdir. Bu çalışmada amaçlı örnekleme yöntemlerinden kolay ulaş̧labilir örnekleme yöntemi tercih edilmiştir.

\section{Veri Toplama Araçları}

$\mathrm{Bu}$ çalışmada veri toplama aracı olarak yarı yapılandırılmış öğrenci görüşlerini belirleme formu ve öğrenci projeleri kullanılmıştır.

Yarı Yapılandırılmış Öğrenci Görüşlerini Belirleme Formu. Araştırmada öğretmen adaylarını eğitsel dijital oyun tasarlama sürecine yönelik görüşlerini belirlemek amacıyla, araştırmacılar tarafından geliştirilen öğrenci görüşlerini belirleme formu kullanılmıştır. Öğrenci görüşlerini belirleme formu, altı maddeden oluşmuştur. Araştırmacılar tarafından hazırlanan bu form uygulanmadan önce, eğitim teknolojisi alanında iki uzmanın görüşüne sunulmuştur. Uzman görüşleri sonucunda formdaki madde sayısında değişme olmamıştır. Uzmanlarca getirilen öneriler maddelerin içeriğine yönelik olmuştur. Uzmanlardan gelen dönüt ve düzeltmeler doğrultusunda forma son hali verilmiştir. Ögrenci Görü̈şlerini Belirleme Formunda yer alan maddeler Ek C'de sunulmuştur.

Öğrenci Projeleri. Eğitsel Bilgisayar Oyunları Tasarımı dersi kapsamında öğrenciler ortaokul eğitim programının inceleyerek bir veya birden fazla kazanımı ele alan bir oyun senaryosu hazırlamışlardır. Bu oyun senaryosu bağlamında seçtikleri kazanımları ele alan bir oyun tasarlamışlardır. Bu bağlamda da öğrenciler dönem sonunda projeler üretmiştir. Öğrencilerin ortaya koyduğu projeler Tasarımsal ve Eğitsel açıdan incelenmiştir (bkz. Ek A, Ek B).

\section{Uygulama ve Veri Toplama Süreci}

Eğitsel dijital oyun tasarlama süresi toplamda 14 hafta sürmüştür. Uygulama öncesinde veri toplama araçlarının oluşturulması, uzman görüşlerinin alınması ve uzman görüşünün alınarak veri toplama aracına son şeklinin verilmesi çalışması yapılmıştır. Uygulama öncesi uygulama planı yapılarak haftalık konu dağılımı hazırlanmıştır. Ayrıca derste kullanılacak etkinlikler ve materyaller geliştirilmiş̧ir.

Uygulama sürecinin başında öğretmen adayları beşer kişilik altı gruba ayrılmışıtır. Gruplar başlangıçta ele alınacak kazanımlar ve içerikle ilgili araştırma yapmıştır. Konu belirlendikten sonra hazırlayacakları oyunun senaryosunu, sahne, dekor ve karakterlerine karar vermişlerdir. Seçilen karakterlerin, sahne ve dekorun tasarımını gerçekleştirdikten sonra bunları Scratch programı ile birleştirmişlerdir. Süreç sonunda oyunun hatasız çalışıp çalışmadığı kontrol ederek sınıf ortamında oyunlarını paylaşmışlardır. Ayrıca çalışmaları ile ilgili bir proje raporu hazırlayarak, proje amacı, proje içeriği, belirlenen kazanımlar ve içerik, hedef kitle, hedef kitleye uygunluk durumu raporlandırılmıştır (Ek A, Ek B). Uygulama sonrasında katılımcılardan yarı yapılandırılmış öğrenci görüşlerini belirleme formu ile veri toplanmıştır. Verilerin toplanması gönüllülük esasıyla gerçekleştirilmiştir.

Uygulama süreci, öncesi ve sonrasına dair ayrıntılar Tablo 1'de sunulmuştur. 
Tablo 1

Araştırma Süreci

\begin{tabular}{|c|c|c|}
\hline Uygulama Süreci Öncesi & Uygulama (1.Hafta...14. Hafta) & Uygulama Sonrası \\
\hline $\begin{array}{l}\text { Veri toplama araçlarının } \\
\text { oluşturulması }\end{array}$ & $\begin{array}{l}\text { İşbirlikli grupların oluşturulması } \\
\text { (1. Hafta) }\end{array}$ & $\begin{array}{l}\text { Veri Toplama Araçlarının } \\
\text { Uygulanması }\end{array}$ \\
\hline $\begin{array}{l}\text { Uzman görüşünün alınarak veri } \\
\text { toplama aracına son şeklinin } \\
\text { verilmesi }\end{array}$ & $\begin{array}{l}\text { Proje çalışmaları için ortaokul matematik dersi } \\
\text { öğretim programının incelenmesi } \\
\text { (2. Hafta) }\end{array}$ & \\
\hline Uygulama planının yapılması & $\begin{array}{l}\text { Proje çalışmalarına paralel olarak Scratch } \\
\text { programının tanıtımı, haftalık Scratch uygulamaları } \\
\text { ve çevrim-içi kaynak paylaşımları } \\
\text { (2. Hafta-10. Hafta) }\end{array}$ & \\
\hline Haftalık konu dağılımının yapılması & $\begin{array}{l}\text { Proje çalışmalarının aşamaları: } \\
\text { Ele alınacak kazanımlar ve içeriklere karar verme } \\
\text { (2. hafta) }\end{array}$ & \\
\hline \multirow[t]{8}{*}{$\begin{array}{l}\text { Ders etkinliklerinin ve } \\
\text { materyallerin hazırlanması }\end{array}$} & $\begin{array}{l}\text { Ele alınacak kazanımlar ve içerikle ilgili araştırma } \\
\text { (3. hafta-5.hafta) }\end{array}$ & \\
\hline & $\begin{array}{l}\text { Hazırlanacak oyunun senaryosunu yazma } \\
\text { (6. hafta-8. hafta) }\end{array}$ & \\
\hline & $\begin{array}{l}\text { Oyunun hikaye kartlarının çizimi } \\
\text { (9. hafta-10. hafta) }\end{array}$ & \\
\hline & $\begin{array}{l}\text { Tasarlanan senaryo, karakter, sahne ve dekorun } \\
\text { geliştirilmesi } \\
\text { (11. hafta-13. hafta) }\end{array}$ & \\
\hline & $\begin{array}{l}\text { Ses kayıtlarının yapılmas1 } \\
\text { (11. hafta-13. hafta) }\end{array}$ & \\
\hline & $\begin{array}{l}\text { Scratch programı ile multimedyanın birleştirilmesi } \\
\text { (11. hafta-13. hafta) }\end{array}$ & \\
\hline & $\begin{array}{l}\text { Oyunun hatasız çalışıp çalışmadığ kontrol edilmesi } \\
\text { (13.hafta-14. hafta) }\end{array}$ & \\
\hline & $\begin{array}{l}\text { Grup Sunumlar1 ve proje raporu hazırlama } \\
\text { (13.hafta-14. hafta) }\end{array}$ & \\
\hline
\end{tabular}

\section{Veri Analizi}

Verilerin analizinde içerik analizi tekniğinden yararlanılmıştır. İçerik analizinde temel amaç, toplanan verileri açıklayabilecek kavramaları ortaya çıkarmaktır. Betimsel analiz verilerin özetlenmesi ve yorumlanması için tasnifini içerirken, içerik analizi ile veriler daha derin bir işleme tabi tutulur. Böylece betimsel analiz ile elde edilemeyen kavram ve temalar içerik analiz sonucu bir araya getirilerek okuyucunun anlayabileceği şekilde organize edilir (Yıldırım ve Şimşek, 2006).

Analiz sürecinde, toplanan veriler düzenlenmiş ve hazırlanan ürünler detaylıca incelenmiştir. Çalışma süresince toplanmış olan ham veriler araştırmacı tarafından açık kodlama yöntemi ile kodlanmıştır. Açık kodlama ile veri parçaları (cümle, proje bölümü) sorgulanarak içinde barındırdığı anlam ortaya çıkarılmaya çalışılmıştır. Araştırmacılar verileri bütün olarak inceleyerek, verileri ilk okumada yüzeysel olarak kodlamıştır. İkinci okumada muhtemel kodlar belirlemiştir. Üçüncü okumada benzer kodlar tek bir kod altında toplamıştır. Dördüncü okumada kodların yer alacağı temalar saptanmıştır. Beşinci okumada kod ve tema uyumları tekrar gözden geçirilmiş ve kategorilere son hali verilmiştir.

$\mathrm{Bu}$ çalışmalar sonucunda taslak form (açık kodlama sonucu ilk oluşturulan kod-tema-kategori ilişkilerini gösteren liste) oluşturulmuştur. Çalışmadan elde edilen ham veriler bir alan uzmanına gönderilmiş ve bu uzman tarafından kodlanmıştır. Alan uzmanı Bilgisayar ve Öğretim Teknolojileri alanında lisans, yüksek lisans ve doktorasını tamamlamış ve Matematik eğitiminde oyun tasarlama ile ilgili konuda deneyime sahiptir. Kodlamanın güvenirliği için kodlayıcılar arası güvenirlik katsayı hesaplanmıştır. Her iki kodlayıcının vermiş olduğu ortak kod sayısının, toplam kod sayısına bölünmesiyle elde edilen güvenirlik yüzdesi \% 89'dur (127(ortak kod)/143(toplam kod)) (Miles ve Huberman, 1994). Kodlamalar arası farklılıklar üzerinde araştırmacılarca uzlaşmaya varılmıştır. Ayrıca tablolarda verilen frekanslar öğrenci sayısını değil kodların sayısını göstermektedir. Kodların kodlanma sıklığını sunarken frekans (f) kullanılmışır. 
Öğrenci projelerinin incelenmesinde de içerik analizi aşamaları uygulanmıştır. Oyunların tasarımsal özelliklerine ilişkin incelenen özellikler örtük özellikler değildir. Oyunların analizinde tasarımsal açıdan incelenmesi gereken tüm unsurlar listelenmiştir. Bunlar renk ve arkaplan kullanımı, yönergelerin sunulup sunulmadığı, bilgi seviyelerinin (level kavramı) oluşturulup oluşturulmadığı, zaman sınırlamasının olup olmadı̆̆ı, oyunda kullanıcı performansına yönelik bir puanlama sisteminin olup olmadığı ve oyunda kullanılan karakterlerin kaynağı incelenmiştir. Oyunların incelenmesiyle ilgili kodlayıcılar arası güvenirlik yüzdesi \% 100'dur (55/55).

Öte yandan öğretmen adayları farklı sorular altında bazı düşünceleri tekrar dile getirmişlerdir. Bu nedenle toplam kod sayısı ile öğrenci sayıları birbirinden farklı olabilir.

\section{Geçerlik Güvenirlik Önlemleri/İnandırıcılık}

Araştırmanın geçerliği için farklı kaynaklardan (görüşme ve projeler) planlanan zamanlarda veri toplanmıştır. Yani veri kaynakları çeşitlenmiş̧ir. Araştırma süreci, uygulama süreci, öncesi ve sonrası ayrıntılı olarak açıklanmış ve verilerin analiz süreci ayrıntılandırılarak sunulmuştur. Sonuçlara nasıll ulaşıldığını açıklamak için uygulama sürecinin ayrıntılarını hafta hafta gösteren bir tablo oluşturulmuştur. Güvenirlik için araştırmacıların, süreçte üstlendiği rolü açıklamıştır. Veri analizi sürecinde kodlayıcı güvenirliğine yer verilmiştir. Uygulama süreci açık ve ayrıntılı şekilde rapor edilmiştir.

\section{Araştırmacının/Araştırmacıların Rolü}

Çalışmanın uygulanması sürecinde seçmeli Eğitsel Bilgisayar Oyunları dersinin yürütülmesinde sorumlu olan araştırmacılar, eğitmen olarak, laboratuvar faaliyetlerini yürütmüştür. Bunun yanı sıra öğretim amaçlı yardımcı materyaller hazırlamak, ders içi uygulamaları gerçekleştirmek, öğretmen adaylarına dönütler vermek, proje etkinliklerini yönlendirmek, ders dışından da kaynaklara erişim için çevrim-içi ortam tasarlamak, bu ortamda sorulan sorular ve yardım taleplerini cevaplamak gibi görevleri gerçekleştirmiştir.

\section{Bulgular}

Araştırmanın amacı doğrultusunda oluşturulan araştırma sorularıyla ilgili ulaşılan bulgular aşağıda sırasıyla sunulmuştur.

\section{Öğretmen adaylarının eğitsel dijital oyun tasarımları}

Araştırmanın birinci araştırma sorusu doğrultusunda öğretmen adaylarının altı dijital oyun tasarımları incelenmiş ve tasarımda nelere dikkat ettiklerine ilişkin nitel veri analizi sonucu Tablo 2'de sunulmuştur.

Tablo 2

Öğretmen Adaylarının Oyun Tasarımlarına İlişkin Bulgular

\begin{tabular}{|c|c|c|c|}
\hline Tema & Kod & Alt kodlar & $f$ \\
\hline \multirow{17}{*}{$\begin{array}{l}\text { Tasarımsal ögeler } \\
\text { açısından }\end{array}$} & \multirow{4}{*}{$\begin{array}{l}\text { Renk ve arkaplan } \\
\text { kullanımı }\end{array}$} & Mavi yeșil ağırlıklı renk seçimi & 4 \\
\hline & & Diğer renkler(kırmız, sarı, siyah ağırlıklı) & 2 \\
\hline & & Düz arkaplan seçimi & 4 \\
\hline & & Karmaşık arkaplan seçimi & 2 \\
\hline & \multirow{3}{*}{ Yönergelerin sunumu } & Yeterince yönerge sunulmuş & 2 \\
\hline & & Kısmen yönerge sunulmuș & 1 \\
\hline & & Yönerge sunulmamış & 3 \\
\hline & \multirow{2}{*}{$\begin{array}{l}\text { Bilgi Seviyeleri (Level } \\
\text { belirleme) }\end{array}$} & Var & 1 \\
\hline & & Yok & 5 \\
\hline & \multirow{2}{*}{ Zaman sinırlaması } & Var & 1 \\
\hline & & Yok & 5 \\
\hline & \multirow{2}{*}{ Puanlama } & Var & 5 \\
\hline & & Yok & 1 \\
\hline & \multirow{4}{*}{ Karakter kullanımı } & İlginç karakterler oluşturma & 1 \\
\hline & & Programda var olan karakterleri kullanma & 4 \\
\hline & & İnternet üzerinden bulduğu sıradan karakterleri kullanma & 1 \\
\hline & & Kendi karakterlerini çizme & 1 \\
\hline
\end{tabular}


Tablo 2 - devam

\begin{tabular}{llll}
\hline Tema & Kod & Alt kodlar & $f$ \\
\hline & & Karmaşık & 2 \\
& & Karmaşı değil & 4 \\
Eğitsel açırdan & & Uygun & 5 \\
& Seçilen eğitsel hedeflere & Kismen uygun & 1 \\
& uygunluk & Uygun değil & 0 \\
\hline
\end{tabular}

Tablo 2'de öğretmen adaylarının eğitsel dijital oyun tasarlama sürecinde tasarımsal ve eğitsel açıdan nelere dikkat ettikleri incelenmiş ve oyun tasarlama sürecinde mavi tonları $(f=4)$ ve düz arka plan renklerini $(f=4)$ kullandıkları, oyunlarda çoğunlukla yönerge kullanmadıkları $(f=3)$ görülmüştür. Öğretmen adaylarının hazırladığı oyunların çoğunluğunda öğrencilerin ön bilgi seviyelerine göre uyarlama $(f=5)$ ve zaman sınırlaması $(f=5)$ yoktur.

Tasarlanan eğitsel dijital oyunların eğitsel açıdan çoğunlukla karmaşık (seviyeler, dallanmalı akış, bilgi düzeyine göre farklı içerik vb.) olmadığı $(f=2)$ sürecinin, ortaokul düzeyi matematik öğretim programında yer alan hedeflere çoğunlukla uygun içerik hazırladıkları görülmektedir. Bu belirlemeyi yaparken ortaokul matematik öğretim programından ele alınan bölümün de öğrencilerce sunumu istenmiştir.

\section{Oyun tasarlama etkinliklerinin mesleki gelişimlerine katkısı hakkındaki görüşleri}

Araştırmanın ikinci araştırma sorusu doğrultusunda öğretmen adaylarının dijital oyun tasarım sürecinin mesleki gelişimlerine katkısı hakkındaki görüşlerine ilişkin nitel veri analizi sonucu Tablo 3'de sunulmuştur.

Tablo 3

Öğretmen Adaylarının Oyun Tasarlama Etkinliklerinin Mesleki Gelişimlerine Katkısı Hakkındaki Görüşleri

\begin{tabular}{lll}
\hline Temalar & Kodlar & $f$ \\
\hline & Teknoloji kullanma yeterliliği kazanma & 7 \\
Teknoloji yeterliği & Yeni teknolojileri kullanmaya uyum sağlama & 4 \\
& Materyal geliştirmek için teknolojiyi kullanma & 2 \\
& Karş1laşılan teknik problemleri çözme & 2 \\
& Farklı teknolojileri kullanma & 2 \\
& Problem çözme becerilerini geliştirme & 5 \\
& Yaratıcılık kazandırma & 3 \\
Akademik/bilişsel & Matematik alanında teknolojiyi kullanabilme yeterlilikleri geliştirme & 3 \\
gelişim & Gereksinimler doğrultusunda bilgi aramayı sağlama & 2 \\
& Kendi gereksinimleri doğrultusunda oyun hazırlama & 2 \\
& Teknoloji entegrasyonuna yönelik öz yeterliği arttırma & 1 \\
& Tasarım yapma ve ürün ortaya koyma & 1 \\
& Mesleki öz güven kazandırma & 1 \\
Pedagojik alanda & Yeni bir öğretim yöntemini uygulama yeterliliği kazanma & 3 \\
gelişim & Farklı öğrencilere öğretim materyalini uyarlama yeterliliği kazanma & 2 \\
& Genel kavramsal bilgileri öğretmek için materyal tasarlama & 2 \\
& Kavramsal yanılgıları gidermek için materyal tasarlama & 1 \\
& Öğrenme çıtıllarını geliştirilen materyal ile tespit etme & 1 \\
Alan bilgisi açısından & Meyin nasıl öğretileceği üzerine düşünme ve çözüm sunma & 1 \\
gelişim & Farklı bir değerlendirme yaklaşımı için bir değerlendirme aracı tasarlama & 1 \\
Olumsuz görüşler & Matematik ve teknolojiyi birleştirme & 3 \\
& Matematik kavramlarının öğretimi üzerine uygulama yapma & 2
\end{tabular}

Tablo 3 incelendiğinde öğretmen adayları eğitsel dijital oyun tasarlama sürecinde en çok akademik alanda gelişim gösterdiği görülmektedir. Eğitsel dijital oyun tasarlama sürecinin akademik alanda en çok problem çözme becerilerini geliştirdiği $(f=5)$, yaratıcılık kazandırdığ $1(f=3)$, matematik alanında teknolojiyi kullanabilme yeterlilikleri geliştirdiği $(f=3)$ görülmektedir. Teknoloji yeterliliği bağlamında bakıldığında öğretmen adaylarının en çok teknoloji kullanma yeterliliği kazanma $(f=7)$ noktasında gelişim sağladıkları görülmüştür. Alan bilgisi açısından $(f=7)$ oyun tasarlama etkinliklerinin matematik öğretimine katkı sağladığı görülmektedir. 
Bunların yanı sıra bazı öğrenciler de eğitsel dijital oyun tasarlama sürecinin mesleki gelişimine herhangi bir katkısı olmadığını belirtmiştir.

Bu bağlamda bazı öğretmen adaylarının görüşlerinden alıntılar şöyledir:

Evet mesleki gelişim açısından yararlı olduğunu düşünüyorum. Teknoloji bilgisinin yanında alan bilgisinin farklı öğretim yollarını öğrenmiş olduk. [Ö12]

İllaki katkısı oluyor. İstediğiniz amaçlara yönelik oyun geliştiriyorsunuz. Bu oyunu geliştirirken senaryo yazıyorsunuz olasılıkları düşünüyorsunuz, yazma ve analitik düşünme beceriniz gelişiyor. Oyunu geliştirirken birçok teknik sıkıntıyla karşılaşıyorsunuz. Grup arkadaşlarınızla olmazsa sınıftaki diğer arkadaşlarınızla çözmeye çalışıyorsunuz. İşbirliği içinde çalışmayı ögreniyorsunuz. Teknolojiye daha çok hakim olursunuz. Sonuçta bir materyal hazırlamakta aslında mesleki özgüven kazandırlyor. [Ö17]

Matematik dersi zor ve sıkıcı bir ders olarak görülüyor. Oyunlar matematik dersini eğlenceli hale getirir ve zenginleştirir. Bir de Matematikte kavram yanllgllarl önemli ve oyunların kavram yanılgılarının giderilmesi için yararlı olduğunu düşünüyorum. Oyun geliştirirken ben de konunun ayrıntılarını senaryolaştırdıkça bazı kavram yanılgılarımı giderdim. [Ö1]

Öğretmen adaylarının eğitsel dijital oyun tasarlama sürecine dair deneyimlerinde zorlayıcı durumlar

Araştırmanın üçüncü araştırma problemi doğrultusunda öğretmen adaylarının eğitsel dijital oyun geliştirme sürecine dair deneyimlerinde zorlayıcı durumlar hakkındaki görüşlerine ilişkin nitel veri analizi sonucu Tablo 4'te sunulmuştur.

Tablo 4

Öğretmen Adaylarının Ĕ̆itsel Dijital Oyun Tasarlama Sürecine Dair Deneyimlerinde Zorlayıcı Durumlara Dair Görüşleri

\begin{tabular}{lll}
\hline Tema & Kod & $f$ \\
\hline & Oyun senaryosu tasarımı & 4 \\
& Oyunda ödül mekanizması kurma & 3 \\
& Güdülenmeyi arttıracak çekiciliği sağlamak & 3 \\
& Hayal edilenin yansıtıllamaması & 3 \\
& Teknoloji kullanımı & 2 \\
& Level oluşturma & 2 \\
Zaman sınırı koyma & 2 \\
Zorlayııı durumlar & Tasarımda elde edilecek skorla ilgili düzenlemeler & 2 \\
& Yaş düzeyininin seveceği karakter seçimi & 2 \\
& Çok kullanıcılı oyun tasarlayamama & 2 \\
& Arayüzlerdeki resimlerin tasarımı & 2 \\
& İçeriğin müfredata uygunluğu sağlama & 2 \\
İçeriğin sunumunun nasıl olacağının seçimi & 2 \\
& Yönergeleri istenilen şekilde düzenleyememe & 1 \\
& & 1 \\
\hline
\end{tabular}

Tablo 4 incelendiğinde öğretmen adaylarının dijital oyun tasarlama sürecinde en çok zorlandıkları durumun oyun senaryosu tasarlama olduğu görülmektedir. Yeni bir yöntem olarak oyun ile matematik öğretimi konusunda öğretmen adaylarının sorun yaşadığı ve bu nedenle bir içeriğin oyunla sunumu ve bunun senaryolaştırılması konusunda zorlandığı düşünülmektedir. Diğer kodlara bakıldığında öğretmen adaylarının en çok oyunda ödül mekanizması kurma $(f=3)$, güdülenmeyi arttıracak çekiciliği sağlamak $(f=3)$ ve hayal edilenin yansıtılamaması $(f=3)$ noktasında zorlandığı görülmüştür.

Bu bağlamda bazı öğretmen adaylarının görüşlerinden alıntılar şöyledir:

Oyun tasarlarken en zoru sürece başlamaktı. Hangi kazanımı seçeceğimize karar veremedik. Kazanımı seçtik. İçerik yazmakta çok zorlandık. Kısacası eğitsel oyunlarda en zorlayıcı şey içeriği ve oyunun senaryosunu belirlemekti. [Ö2]

Derste en çok tasarladı̆̆ım oyunu oluştururken zorlandım. Oyunda zorluk seviyeleri yapmak istedik. Bunun için çok örnek inceledik. Zaman sınırı ve bazı ölçütler eklemek istedik. Kullandığımız programı daha detaylı ögrenmek için çabaladık. Ayrıca internetten farklı yerlerden bulduğumuz karakterler renk ve yapı açısından uyum göstermedi. Onunla uğraştık. Bir karakterin oyun içinde birden fazla kostümünü kullanmamı gerekti. Ama bunu hazırlamak çok zaman alıcıydı. Dersteki süre yetersizdi. [Ö11] 
Oyunu hazırlarken teknik anlamda zorlandık. Bir de oyunun düzeyi ortaokul öğrencilerine uygun olur mu sorusu üzerinde grup arkadaşlarımla çok düşündük. [Ö15]

\section{Sonuç ve Tartışma}

$\mathrm{Bu}$ çalışmada bir devlet üniversitesinde ilköğretim matematik programında öğrenim gören öğretmen adaylarının eğitsel dijital oyun tasarım süreçleriyle ilgili görüşleri incelenmiştir. Araştırmada öğretmen adaylarının eğitsel dijital oyun tasarlama sürecinde tasarımsal ve eğitsel açıdan nelere dikkat ettikleri görülmüşsür. Renk, arkaplan, karakter seçimi, yönerge, bilgi düzeyleri, dallanmalı yapı kullanımı incelenmiş ve öğretmen adaylarının hazırladığı oyunların çoğunluğunda öğrencilerin ön bilgi seviyelerine göre uyarlama, zaman sınırlaması ve yönerge kullanımı olmadığı görülmüştür. Öğretmen adayları eğitsel açıdan farkındalıklarının olduğunu ancak teknik bazı yetersizliklerden ve zaman kısıtlamasından dolayı tasarladıklarını gerçekleştiremediklerini bildirmiştir. Becker'e (2007) göre ne zaman, nasıl ve hangi oyunların özellikle eğitim amaçlarına hizmet edeceği konusunda öğretmen adaylarının rehberliğe ihtiyaçları vardır. Buradan hareketle öğretim programında öğretmen adayların eğitsel oyun tasarlamayla ilgili daha fazla derse yer verilmesi önerilebilir. Ayrıca Bourgonjon ve diğerleri (2013) bu konuda öğretmen adaylarının oyun tasarlama deneyimi yaşamadan önce, eğitsel oyunlarla ilgili yapılan uygulamalardan haberdar edilmesi gerektiğini önerir.

Araştırma sonuçlarına göre öğretmen adayları eğitsel dijital oyun tasarlama sürecinde en çok akademik/bilişsel olarak gelişim göstermiştir. Eğitsel dijital oyun tasarlama sürecinin akademik alanda en çok problem çözme becerilerini geliştirdiği, yaratıcılık kazandırdığı, matematik alanında teknolojiyi kullanabilme yeterlilikleri geliştirdiği görülmektedir. Öğretmen adayları sürecin problem çözme becerisini geliştirmek için uygun bir ortam sunduğunu belirtmiştir. Teknoloji yeterliliği bağlamında bakıldığında öğretmen adaylarının en çok teknoloji kullanma yeterliliği kazanma noktasında gelişim sağladıkları görülmüştür.

Mevcut çalışmada öğretmen adayları grup olarak eğitsel oyunları tasarlasalar da, bireysel olarak çaba göstermişlerdir. Dahası, katılımcıların çoğu, tasarımlarını kontrol ederken, her adımda tasarımlar hakkında arkadaşlarının veya öğretim elemanının fikirlerini aldıklarını belirtmiştir. Bu geri bildirimlerle oyun tasarımları tasarım ilkeleri açısından daha uygun hale gelmiştir. Böylece öğretmen adaylarının tasarımsal açıdan yeterliliklerinin geliştirilmesine katkı yapılmıştır. Katılımcıların oyun tasarımı etkinliklerinin katkılarıyla ilgili çoğunlukla olumlu tepki gösterdiği görülmekte ve oyun tasarımının mesleki, alan bilgisi ve teknik açıdan katkılarının olduğu sonucuna varılmıştır. Bu sonuçlar, eğitsel dijital oyunların tasarlama sürecinin birçok beceri gerektirdiğinin göstergesidir. Ayrıca oyun tasarlama sürecine ilişkin görüşler, öğretmen adaylarının oyun tasarlama sürecinde becerilerini nasıl yansıttı̆̆ını göstermektedir. Bu çalışmanın bulgularını destekler nitelikte, Ding (2019), oyun tasarımında dikkate alınması gereken faktörlerin oyunun eğitimle bütünleştirilmesinde belirleyici olduğunu belirtmiştir. Ancak tasarımsal ögelerin yaş grubu veya öğrencilerin kişisel özelliklerine göre olumlu ya da olumsuz sonuçları olabileceği vurgulanmıştır. Dolayısıyla gelecek çalışmalarda tasarlanan dijital eğitsel oyunların hedef kitleye uygulanarak geribildirimlerin incelenmesi ve oyunların buna göre iyileştirilmesi önerilebilir.

Öğretmen adaylarının dijital oyun tasarlama sürecinde en çok zorlandıkları durumun oyun senaryosu tasarlama olduğu görülmektedir. Yeni bir yöntem olarak oyun ile matematik öğretimi konusunda öğretmen adaylarının sorun yaşadığı ve bu nedenle bir içeriğin oyunla sunumu ve bunun senaryolaştırılması konusunda zorlandığı düşünülmektedir. Werbach ve Hunter (2012) göre oyun senaryolarının ve oyunlaştırma etkinliklerinin öğrenme performansına katkı sağlayabilmesi için dışsal güdülemeden ziyade içsel güdülenmeye odaklanması gerekir. $\mathrm{Bu}$ nedenle oyun tasarlama süreçlerinde özerklik, yetkinlik ve bağlllık hislerini destekleyici senaryolar geliştirilmelidir. Öğretmen adaylarının oyun senaryosu belirlemede zorlanmalarının bir diğer nedeni ise eğitsel dijital oyunların senaryolarının güdülenmeyi artıracak nitelikte olmasını sağlama çabası olabilir.

Katılımcıların kendi beyanları doğrultusunda veriler elde edilmiştir. Bu çalışmanın katılımcıları daha önceki dönemlerde Bilgisayar kullanımı dersi almış ve birçok derste dijital hikâye tasarımı gerçekleştirmiştir. Bu durumun çalışmanın süreci ve sonuçları üzerinde bir etkisi olabilir. Öte yandan bu uygulamanın yapıldığı dersin ilköğretim matematik öğretiminde ve seçmeli olması oyun tasarım etkinliklerinin gerçekleştirilmesinde, çalışmanın sonuçları üzerinde etkili olabilir. Gelecek çalışmalarda öğretmen adaylarının branşlarına bağlı olarak dijital oyunlara bakışlarında, oyun tasarımlarında ve oyunların tasarımıyla ilgili görüşlerinde farklılaşma olup olmadığıyla ilgili çalışma yapılabilir. İleride yapılacak çalışmalarda tasarlanan eğitsel dijital oyunların etkililiğini değerlendirecek deneysel çalışmalar yapılabilir. $\mathrm{Bu}$ şekilde tasarlanan eğitsel dijital oyunları kullanan öğrencilere etkileri de değerlendirilebilir. Ayrıca göz hareketlerini izleme teknolojisiyle, tasarlanan oyunların tasarım özellikleri incelenebilir. İlköğretim matematik öğretmeni adayları ile yapılan bu çalışmanın diğer bölümde öğrenim gören öğretmen adayları ile tekrarlanarak genellenebilirliği artırılabilir. 


\section{Kaynakça/References}

Becker, K. (2007). Digital game-based learning once removed: Teaching teachers. British Journal of Educational Technology, 38(3), 478-488. doi:10.1111/j.1467-8535.2007.00711.x

Berns, A., Gonzalez-Pardo, A., \& Camacho, D. (2013). Game-like language learning in 3-D virtual environments. Computers \& Education, 60(1), 210-220. doi:10.1016/j.compedu.2012.07.001

Bourgonjon, J., De Grove, F., De Smet, C., Van Looy, J., Soetaert, R., \& Valcke, M. (2013). Acceptance of game-based learning by secondary school teachers. Computers \& Education, 67, 21-35. doi:10.1016/j.compedu.2013.02.010

Büyüköztürk, Ş., Çakmak, E. K., Akgün, K. Ş., Karadeniz, Ş. ve Demirel, F. (2012). Bilimsel araştırma yöntemleri (11. Baskı). Ankara: Pegem Akademi.

Day, E. A., Arthur J, W., \& Gettman, D. (2001). Knowledge structures and the acquisition of a complex skill. Journal of Applied Psychology, 86(5), 1022. doi:10.1037/0021-9010.86.5.1022

De Lisi, R., \& Wolford, J. L. (2002). Improving children's mental rotation accuracy with computer game playing. The Journal of Genetic Psychology, 163(3), 272-282. doi:10.1080/00221320209598683

Dede, C., Ketelhut, D., \& Nelson, B. (2004, April). Design-based research on gender, class, race, and ethnicity in a multi-user virtual environment. In American educational Research Association Conference, San Diego, CA, Retrieved (Vol. 2807).

Ding, L. (2019). Applying gamifications to asynchronous online discussions: A mixed methods study, Computers in Human Behavior, 91, 1-11. doi:10.1016/j.chb.2018.09.022

Durak, H. ve Seferoğlu, S. S. (2017). Öğretmenlerin teknoloji kullanım yeterliklerinde etkili olan faktörlerle ilgili bir inceleme. İçinde B. Akkoyunlu, A. İşman ve H. F. Odabaşı (Ed.), Eğitim teknolojileri okumaları 2017, (ss. 537-556). Ankara: TOJET.

Durak, H. ve Seferoğlu, S. S. (2018). Ortaokul öğrencilerinin akıllı telefon kullanımları ve bağımlılık düzeyleriyle ilgili unsurlar. Eğitim Teknolojisi Kuram ve Uygulama, 8(1), 1-23. doi:10.17943/etku.288822

Foster, A., Katz-Buonincontro, J., \& Shah, M. (2011, March). Designing a game-based learning course: K-12 integration and pedagogical model. In Society for Information Technology \& Teacher Education International Conference (pp. 1477-1483). Association for the Advancement of Computing in Education (AACE).

Furió, D., GonzáLez-Gancedo, S., Juan, M. C., Seguí, I., \& Rando, N. (2013). Evaluation of learning outcomes using an educational iPhone game vs. traditional game. Computers \& Education, 64, 1-23. doi:10.1016/j.compedu.2012.12.001

Gall, M. D., Borg, W. R., \& Gall, J. P. (1996). Educational research: An introduction. (6th ed.) NY, England: Longman Publishing.

Gee, J. P. (2007). Good video games+good learning (pp. 1-82). New York: Peter Lang.

González-González, C., \& Blanco-Izquierdo, F. (2012). Designing social videogames for educational uses. Computers \& Education, 58(1), 250-262. doi:10.1016/j.compedu.2011.08.014

Gros, B. (2007). Digital games in education: The design of games-based learning environments. Journal of Research on Technology in Education, 40(1), 23-38. doi:10.1080/15391523.2007.10782494

Güleroğlu, M. (2015). Pre-service teachers' beliefs, experiences and perceptions on mobile games. (Unpublished Master's Thesis). Middle East Technical University, Turkey.

Karadağ, R. (2015). Pre-Service teachers' perceptions on game based learning scenarios in primary reading and writing instruction courses. Educational Sciences: Theory and Practice, 15(1), 185-200. doi:10.12738/estp.2015.1.2634 
Karataş, E. (2014). Eğitimde oyunlaştırma: Araştırma eğilimleri. Ahi Evran Üniversitesi Kırşehir Eğitim Fakültesi Dergisi, 15(2),315-333.

Kebritchi, M. (2010). Factors affecting teachers' adoption of educational computer games: A case study. British Journal of Educational Technology, 41(2), 256-270. doi:10.1111/j.1467-8535.2008.00921.x

Kim, B. (2015). Designing gamification in the right way. Library Technology Reports, 51(2), 29-35.

Miles, M. B., \& Huberman, A. M. (1994). Qualitative data analysis: An expanded sourcebook. (2nd ed.). California: SAGE Publications.

Noraddin, E., \& Kian, N. T. (2015). Three learning potentials in digital games: perception of Malaysian university teachers. Journal of e-Learning and Knowledge Society, 11(2), 143-160.

Razak, A. A., Connolly, T., \& Hainey, T. (2011, October). The use of Games-Based Learning Within the Curriculum for Excellence: The Teachers' Perspective. In European Conference on Games Based Learning (p. 1). Academic Conferences International Limited.

Romero, M., \& Barma, S. (2015). Teaching pre-service teachers to integrate serious games in the primary education curriculum. International Journal of Serious Games, 2(1), 45-54. doi:10.17083/ijsg.v2i1.43

Rosas, R., Nussbaum, M., Cumsille, P., Marianov, V., Correa, M., Flores, P., ... \& Rodriguez, P. (2003). Beyond Nintendo: design and assessment of educational video games for first and second grade students. Computers \& Education, 40(1), 71-94. doi:10.1016/S0360-1315(02)00099-4

Sancar Tokmak, H. (2015). Pre-service teachers' perceptions on TPACK development after designing educational games. Asia-Pacific Journal of Teacher Education, 43(5), 392-410. doi:10.1080/1359866X.2014.939611

Sardone, N. B. \& Devlin-Scherer, R. (2010). Teacher candidate responses to digital games: 21st-century skills development. Journal of Research on Technology in Education, 42(4), 409-425. doi:10.1080/15391523.2010.10782558

Sarıtepeci, M., Durak, H. ve Seferoğlu, S. S. (2016). Öğretmenlerin öğretim teknolojileri alanında hizmet-içi eğitim gereksinimlerinin FATİH projesi kapsamında incelenmesi. Turkish Journal of Computer and Mathematics Education, 7(3), 601-620. doi:10.16949/turkbilmat.277873

Siko, J. P., \& Barbour, M. K. (2012). Homemade PowerPoint games: Game design pedagogy aligned to the TPACK framework. Computers in the Schools, 29(4), 339-354. doi:10.1080/07380569.2012.734430

Somyürek, S. (2014). Öğrenme sürecinde z kuşağının dikkatini çekme: Artırılmış gerçeklik. Eğitim Teknolojisi Kuram ve Uygulama, 4(1), 63-80. doi:10.17943/etku.88319

Stupiansky, W., Stupiansky, S., \& Nicholas, G. (1999). Games that teach. Instructor-Primary, 108(5).

Werbach, K., \& Hunter, D. (2012). For the win: How game thinking can revolutionize your business. Philadelphia, PA: Wharton Digital Press.

Yıldırım, A. \& Şimşek, H. (2008). Nitel araştırma yöntemleri.(7. Baskı). Ankara: Seçkin Yayıncılık.

Yıldız, H., Sarıtepeci, M. ve Seferoğlu, S. S. (2013). FATïH Projesi Kapsamında Düzenlenen Hizmet-İçi Eğitim Etkinliklerinin Öğretmenlerin Mesleki Gelişimine Katkılarının ISTE Öğretmen Standartları Açısından İncelenmesi. Hacettepe Üniversitesi Eğitim Fakültesi Dergisi [Hacettepe University Journal of Education], Özel Sayl (1), 375-392.

Yin, R. K. (2003). Case study research: Design and methods. (3. Bask1). Thousand Oaks, CA: Sage. 


\section{Ek A}

\section{Bir Grubun Oyun Tasarım Raporu}

Oyunu oynamak için gerekli bilgileri, oyunun amacını, hangi kazanım için hazırlandığı, hazırlanma süreci hakkında bilgi verilmektedir. Gerçekleştirme, bir projenin hayata geçmesi sürecidir. Bu süreçte araştırma, tartışma, seçme ve deneme yanılmayla en doğru olanını bulma yer almalıdır. İçerisindeki bilgiler projeyle ilgili bilirkişiye sunulur. Proje geliştirme sürecinde gerçekleştirim bölümü, projenin gerçekleştiği somut olarak hayata geçtiği bölüm olduğu için önemlidir ve sonraki proje aşamasına ulaşmamızı, önceki proje aşamasını sorgulamamız açısından etkiler.

Bizim grubumuzun gerçekleştirim sürecindeki amacı, ortaokul matematik öğretim programında 5. Sinıflar için yer alan "5.1.3.4. bir doğal sayı ile bileşik kesri karşılaştırır." kazanımını öğrencilere kazandırabileceğimiz bir oyun tasarlamaktı. Gerçekleştirim sürecinde buna uygun olarak öğrencilerin her doğal sayıyı aslında paydası 1 olan bir bileşik kesir olduğunu bilmesi üzerine bir oyun tasarladık.

Projeyi gerçekleştirirken Scratch programında sahne geçişlerinde sorunlar yaşadık. KALAN CAN ve SKOR sayılarının istenilen sayıya gelişinde sahne geçiş yapıyor fakat büyücü karakterinin lafını söyleyip bekledikten sonra bu sahne geçişinin olmasını istiyorduk. Youtube ve Scratch programındaki örnekleri inceledik, fakat bu istediğimize uygun örnek bulamadık. Bu sapmanın proje sürecindeki amacımızı etkilediğini düşünmüyoruz.

Scratch programı: Oyunu tasarlama sırasında bu programı kullandık.
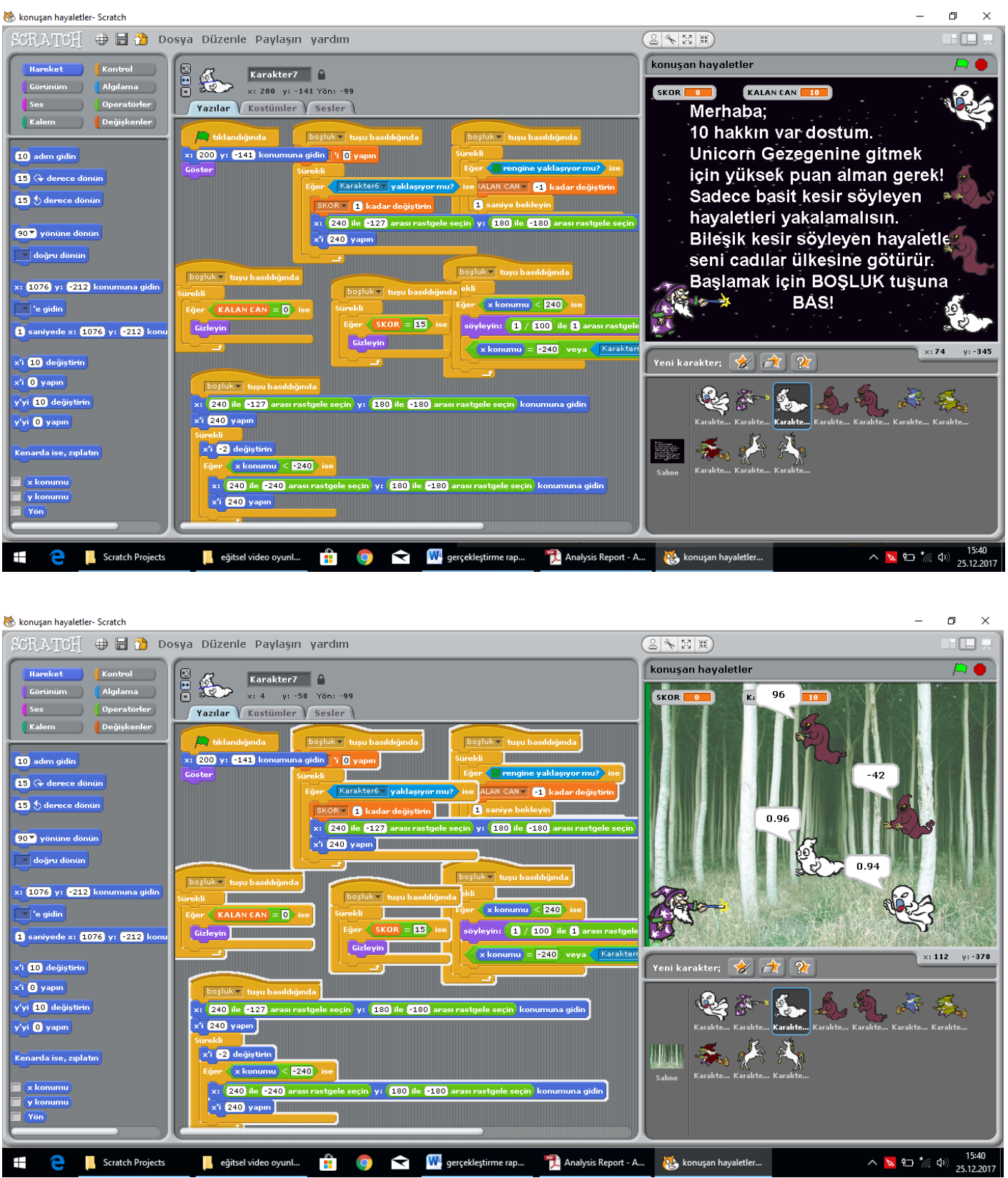

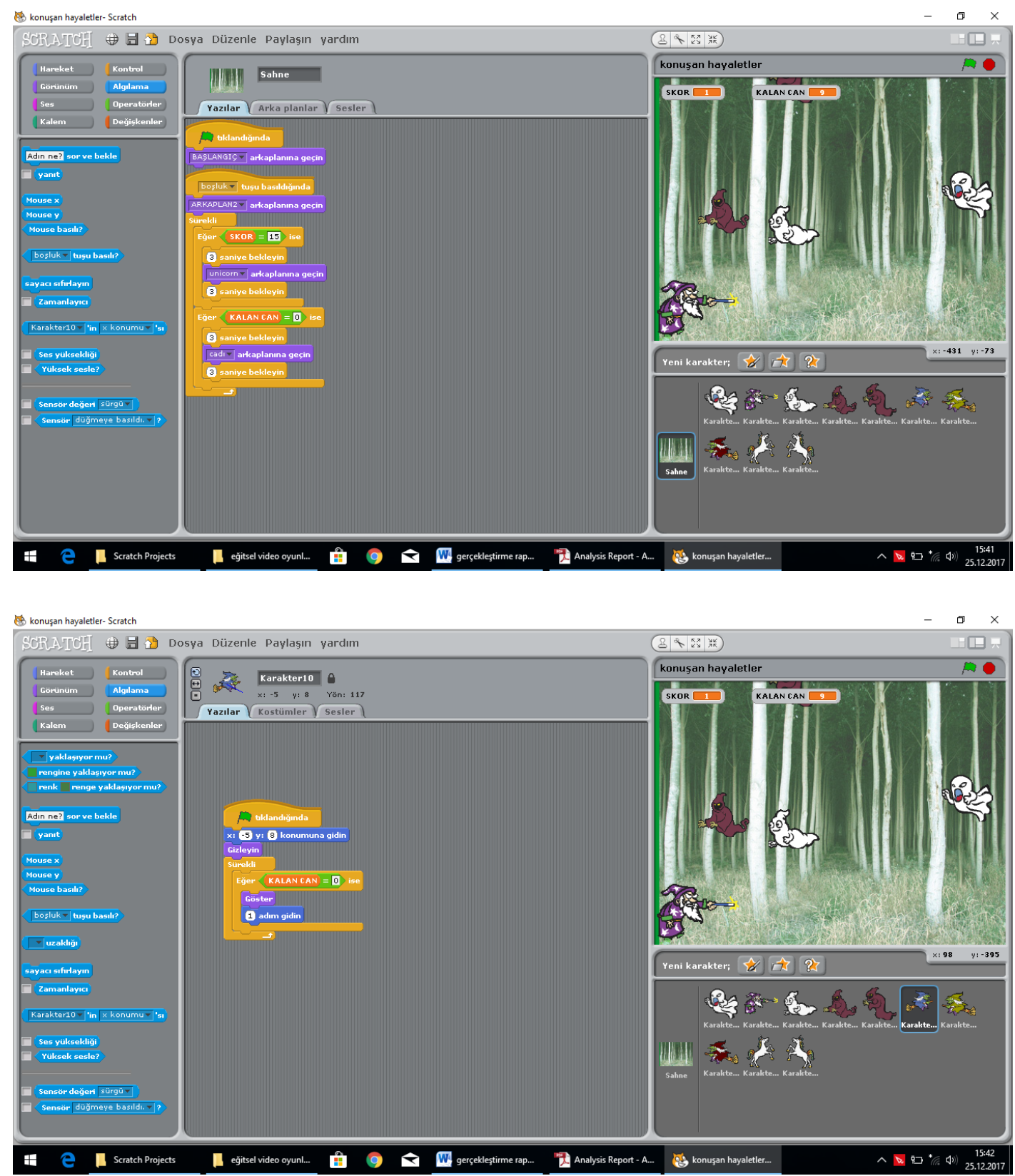

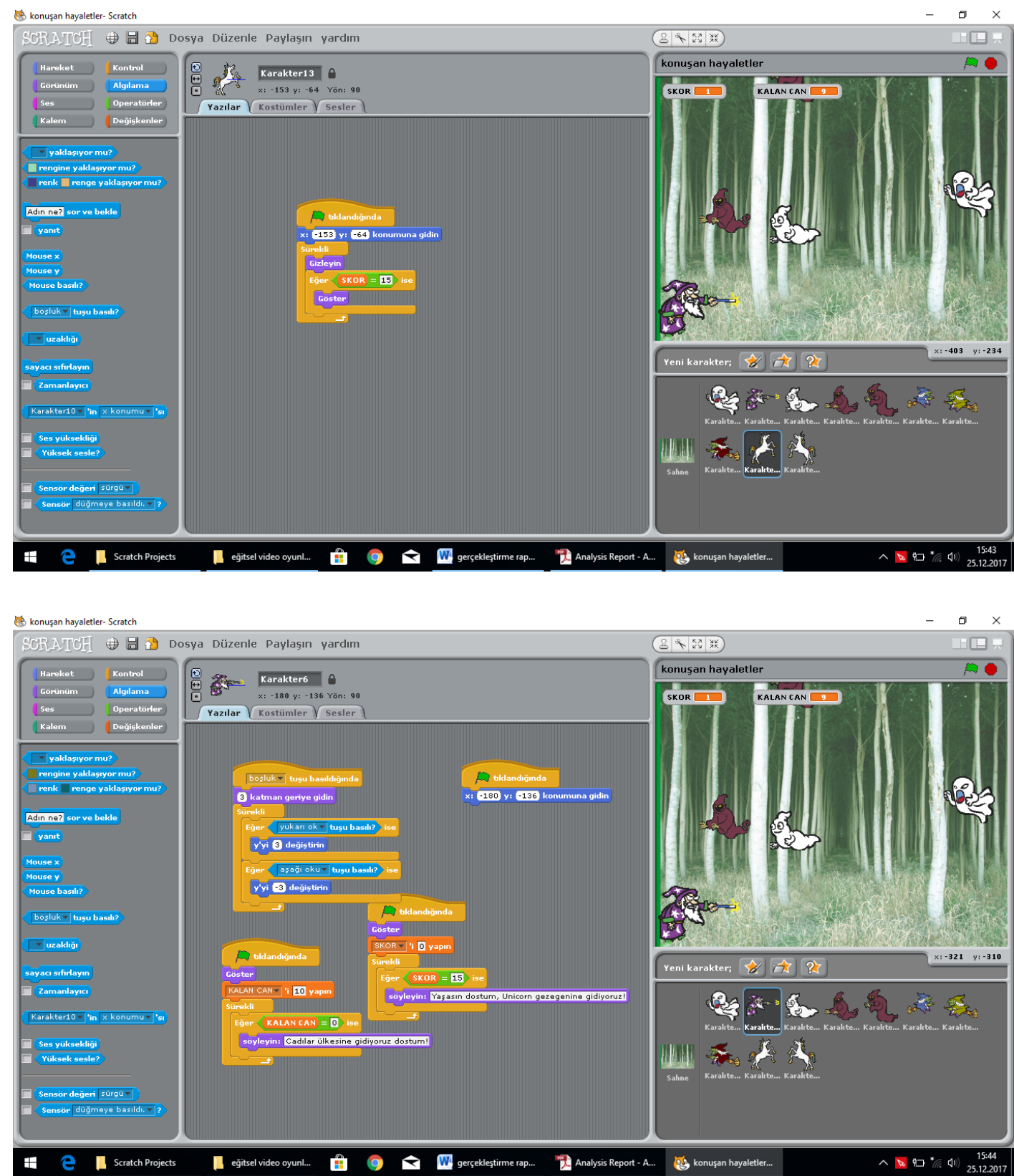

Yazılımın amacı oyuncunun doğal sayıların bileşik kesir olduğu bilgisini ölçmektir. Oyuncunun oynayabilmesi için bilgisayar klavyesinde boşluk, yukarı ok ve aşağı ok tuşlarını kullanma becerisi olmalıdır. 


\section{Ek B}

Öğretmen Adayları Tarafından Tasarlanan Eğitsel Oyunlardan Arayüzler

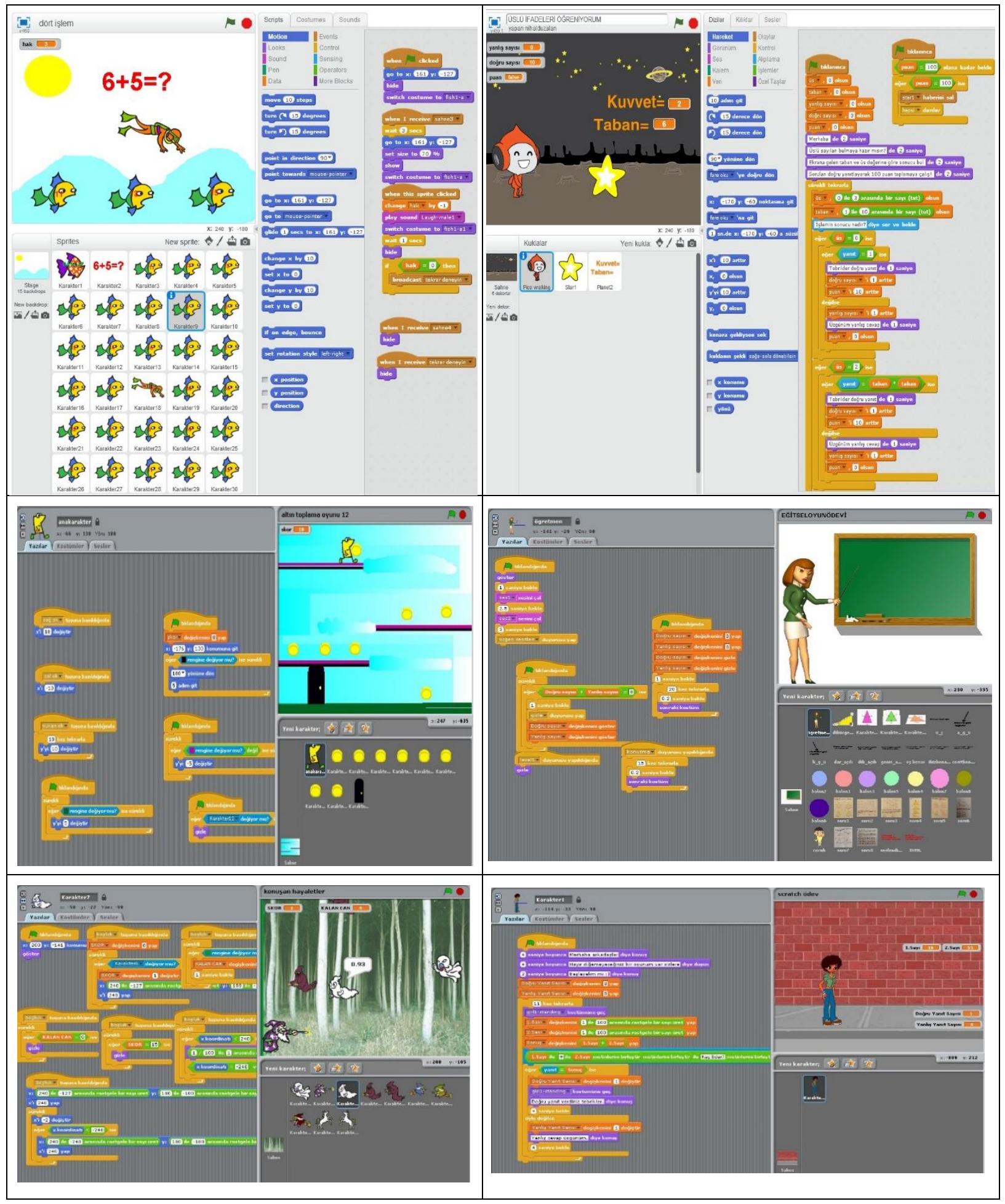




\section{Ek C}

\section{Yarı Yapılandırılmış Öğrenci Görüşserini Belirleme Formu}

1. Eğitsel dijital oyun geliştirme etkinliklerinin kişisel gelişiminize katkısı hakkındaki görüşleriniz nelerdir?

2. Eğitsel dijital oyun geliştirme etkinliklerinin teknoloji yeterlik düzeyinizin gelişimine katkısı olduğunu düşünüyor musunuz?

3. Eğitsel dijital oyun geliştirme etkinliklerinde oyun tasarımında önemli gördüğünüz noktalar nelerdi? Açıklayınız.

4. Eğitsel dijital oyun geliştirme etkinliklerinin mesleki gelişimine katkısı olduğunu düşünüyor musunuz? (Alan bilgisi, teknoloji bilgisi, pedogoji vb.)

5. Eğitsel dijital oyunlar geliştirme ile ilgili öne çıkan sizin için zorlayıcı gelen durumlar nelerdir?

6. Bu dersteki öğrenim sürecinizi değerlendirerek (genel olarak ders ve süreçle ilgili) olumlu ve zorlayıcı durumları ve bu konulardaki deneyimlerinizi açıklayınız. 